\title{
A evolução da Covid-19 e incidência nos óbitos da população idosa: defesa do isolamento horizontal
}

Com o avanço da Covid-19, implementaram-se medidas de enfrentamento da pandemia por meio de práticas preventivas não farmacológicas e isolamento social com o intuito de diminuir a velocidade de contágio e propagação da doença. Neste cenário, observa-se que, a partir das informações dos países que se tornaram epicentro da doença, as consequências sobre a população acima de 60 anos são extremamente preocupantes (muitas vezes fatais) e, mesmo diante dos direitos das pessoas idosas, tais conquistas não minimizam os efeitos da propagação da doença nesta faixa etária, sendo necessária uma decisão que abarque toda a sociedade. Assim, propõe-se analisar a evolução da propagação da Covid-19 nos países mais afetados, com o intuito de saber se as medidas de isolamento adotadas pela Administração Pública são adequadas para dirimir o contágio e o número de óbitos entre as pessoas idosas. Por meio de pesquisa exploratória, foi possível analisar a evolução da Covid-19 e observar seus impactos, principalmente sobre a população idosa, considerada a mais vulnerável. A análise dos dados possibilitou comprovar que nos países com maior incidência de casos, mais de $90 \%$ dos óbitos foram de indivíduos com mais de 60 anos. Tal fato não pode ser desconsiderado pela Administração Pública. Conclui-se que a melhor escolha é pelo isolamento horizontal, pois possibilita, ao longo do tempo, diminuir a propagação do vírus, garantir atendimento hospitalar aos que contraírem a forma grave da doença e reduzir o número de óbitos, principalmente entre os idosos.

Palavras-chave: Pandemia; Covid-19; Isolamento social; Isolamento horizontal; Idosos.

\section{The evolution of Covid-19 and incidence in deaths of the elderly population: defense of horizontal isolation}

\begin{abstract}
With the advancement of Covid-19, measures to combat the pandemic were implemented through non-pharmacological preventive practices and social isolation in order to reduce the speed of contagion. In this scenario, it is observed that, based on information from countries that have become the epicenter of the disease, the consequences for the population over 60 years old are extremely worrying (often fatal), and even in the face of the rights of the elderly, such achievements do not minimize the effects of the disease's spread among the elderly, requiring a decision that embraces the whole of society. Thus, it is proposed to analyze the evolution of the spread of Covid-19 in the most affected countries, in order to find out if the isolation measures adopted by the Brazilian Public Administration are adequate to resolve the contagion and the number of deaths among the elderly. Through exploratory research, it was possible to analyze the evolution of Covid19 and observe its impacts, especially on the elderly population, considered the most vulnerable. The analysis of data from epidemiological bulletins made it possible to prove that, in the countries with the highest incidence of cases, more than $90 \%$ of the total deaths are among individuals over 60 years of age. We conclude that the best choice is for horizontal isolation, because it makes it possible, over time, to reduce the spread of the virus, guarantee hospital care and reduce the number of deaths, especially among the elderly.
\end{abstract}

Keywords: Pandemic; Covid-19; Social isolation; Horizontal insulation; Seniors.

Topic: Gestão Pública

Reviewed anonymously in the process of blind peer.
Received: 07/06/2020

Approved: 29/07/2020
Fábio André Teixeira (iD)

Universidade Federal de Viçosa, Brasil

http://lattes.cnpq.br/2311130632500023

http://orcid.org/0000-0003-3527-723X

fateixeira.ufv@gmail.com

Carlos Eduardo Artiaga Paula (ii)

Universidade Federal de Viçosa, Brasil

http://lattes.cnpq.br/3708562405604246

http://orcid.org/0000-0001-6927-9239

carlosedart@gmail.com

Antônio Marcos de Queiroz (ic)

Universidade Federal de Goiás, Brasil

http://lattes.cnpq.br/3494140564037466

http://orcid.org/0000-0001-9050-2781

antonio.mq10@gmail.com

\author{
Diego Queiroz Melo (iD \\ Universidade Federal de Viçosa, Brasil \\ http://lattes.cnpq.br/4340709191817208 \\ http://orcid.org/0000-0003-3858-3144 \\ diego.queiroz@ufv.br \\ Gustavo Marcilio Vieira da Silva (it \\ Universidade Federal de Viçosa, Brasil \\ http://lattes.cnpq.br/6738316500296361 \\ http://orcid.org/0000-0003-4595-8565 \\ gustavomarciglio@gmail.com
}

Referencing this:

TEIXEIRA, F. A.; PAULA, C. E. A.; QUIEROZ, A. M.; MELO, D. Q.; SILVA, G. M. V.. A evolução da Covid-19 e incidência nos óbitos da população idosa: defesa do isolamento horizontal. Revista Brasileira de Administração Científica, v.11, n.3, p.167-182, 2020. DOI: http://doi.org/10.6008/CBPC2179-684X.2020.003.0012 


\section{INTRODUÇÃO}

A Covid-19 (Coronavirus Disease 2019) foi detectada na China em 31 de dezembro de 2019 na província de Hubei, cuja capital é Wuhan, e se espalhou para o resto do mundo (210 países e territórios), colocando em xeque os sistemas de saúde, econômico e social das nações e, em consequência, demandou ações estratégicas para evitar a propagação da epidemia. Até o dia 30 de abril de 2020 em todo o mundo foram contabilizados 3.271 .567 casos de coronavírus com 231.251 mortes. O rápido avanço da doença forçou a Organização Mundial de Saúde (OMS) a classificá-la como pandemia no dia 11 de março de 2020 e, para mitigar o seu impacto, os países adotaram práticas preventivas não farmacológicas, como distanciamento 'espacial' ou 'social', uso de máscaras protetoras e orientações para quesitos de higiene pessoal, como lavagem das mãos, uso de álcool em gel e cartilhas de conscientização, que foram amplamente implementadas (FENZ et al., 2020).

Mesa et al. (2020) apontam que as estratégias adotadas de "distanciamento social" incluíram o fechamento de instituições educacionais e locais de trabalho, cancelamento de reuniões de massa, isolamento de casos suspeitos ou confirmados, quarentena de pessoas em contato com casos confirmados, recomendações de permanência em casa e até quarentena obrigatória em algumas cidades. Rosa (2020) defende que a medida mais importante para contenção do contágio é pelo isolamento social, uma vez que a rápida propagação do novo coronavírus tem feito muitas vítimas em todo o mundo. Ou seja, as pessoas devem permanecer em casa, desde que possuam esse privilégio, e evitar as saídas às ruas e o contato próximo com outras pessoas, mesmo que elas morem na mesma residência.

Um isolamento horizontal estabelece a reclusão dos indivíduos em suas casas por um período determinado, sem distinção de faixa etária ou doenças pré-existentes e com o cumprimento das recomendações dos órgãos de saúde, diminuindo o contato entre pessoas e os subsequentes contágio e propagação do vírus. Esta medida difere do isolamento vertical, que consiste no isolamento apenas dos grupos de risco, quais sejam pessoas idosas a partir dos 60 anos e aquelas com doenças pré-existentes, como diabetes, problemas cardíacos ou respiratórios.

Contudo, países como a Itália, Espanha e França, que são referência na melhoria do nível de bemestar do idoso, não passaram incólumes pela Covid-19 e tiveram elevado percentual de mortes de pessoas acima de 60 anos, mesmo adotando medidas de isolamento social. Isto porque não é a condição física ou de saúde que evita o contágio, e sim, políticas nacionais de contenção à propagação da doença. Ademais, nem todos os que contraírem a doença necessariamente apresentarão Síndrome Respiratória Aguda Grave (SRAG), não sendo necessário sua hospitalização e o uso de equipamentos, como os respiradores, por exemplo. No entanto, como a população idosa apresenta outras doenças, consideradas no grupo de risco, as mortes devem se elevar a partir do momento em que contraírem a Covid-19.

Diante disto, a problemática do trabalho é responder ao seguinte questionamento: Ao considerar o avanço da Covid-19, quais os principais efeitos sobre o número de óbitos da população idosa e se as medidas de isolamento social ajudam a mitigar os seus impactos. Baseada nessa problemática, a hipótese é de que o 
crescente aumento no número de casos da Covid-19 impulsione o número de óbitos entre a população idosa, mais do que o habitual. Questiona-se, portanto, se no Brasil, a Constituição Federal de 1988, a Política Nacional do Idoso de 1994 e a criação do Estatuto do Idoso, dentre outras políticas relevantes, conjugadas com as decisões tomadas, serão capazes de minorar os efeitos das elevadas taxas de óbitos da população idosa, uma vez que procuram reforçar seus direitos, melhorar o padrão de vida e garantir melhor nível de bem-estar, fatores mitigadores da taxa de mortalidade e aumento da expectativa de vida. Entretanto, diante de uma pandemia, estas conquistas são colocadas em xeque, uma vez que não se pode garantir que não haverá contágio e, consequentemente, por apresentarem sistemas imunológicos menos fortalecidos, a ocorrência da doença pode ser fatal.

Segundo a Câmara dos Deputados (2020), diversos projetos de lei estão sendo apresentados para garantir a proteção específica e assegurar os direitos dos idosos, neste cenário da pandemia, são eles: o Projeto de Lei $971 / 2020$, os asilos e instituições de idosos estabelecerem regras de um visitante por semana com duração de 15 minutos, com os devidos equipamentos de proteção individual; o Projeto de Lei 1476/2020 que concede isenção de imposto de renda aos maiores de 65 anos e aposentados com renda até dez salários mínimos, alterando a Lei 7.713/1988 que trata do IR; o Projeto de Lei 1.237/2020 que isenta do pagamento da contribuição o custeio da iluminação pública os idosos acima de 65 anos, proprietário do imóvel e com renda até três salários mínimos, com consumo mensal de energia de até 300 quilowatts; o Projeto 965/2020 que prevê a suspensão temporária dos contratos de créditos entre instituições financeiras e aposentados e o perdão total de dívidas dos pensionistas que recebem até três salários mínimos; o Projeto de Lei 1.026/2020 que prevê obrigatoriedade de 100\% de qualquer benefício ou assistência social recebido pelo idoso para custeio das entidades filantrópicas de longa permanência, devido ao alto custo e gasto de internação e; o Projeto de Lei 818/2020, que torna obrigatória a internação hospitalar de pessoas com mais de 79 anos que estejam com o coronavírus, prevendo ainda a reserva de 10\% dos leitos dos hospitais para este tipo de internação.

Traça-se como objetivo geral analisar a evolução da propagação da Covid-19 nos países mais afetados com o intuito de saber se as medidas de isolamento adotadas pela administração pública são adequadas para dirimir o contágio e o número de óbitos entre a população idosa. Os objetivos específicos são: apresentar ao longo do tempo a evolução da Covid-19 com base nas informações da OMS; elencar os principais países que se tornaram epicentro da Covid-19 e as medidas adotadas para conter o avanço do vírus; apresentar um histórico das conquistas relacionadas ao direito da pessoa idosa no Brasil e no mundo; analisar os boletins epidemiológicos, disponibilizados pelos órgãos de contenção, controle e prevenção da Covid-19 e suas notificações de casos confirmados e de óbitos.

O trabalho está estruturado em cinco seções, considerando a introdução e a conclusão. A seção dois aborda a revisão da literatura com as principais medidas de combate à Covid-19; a seção três apresenta a metodologia de pesquisa; na quarta seção são apresentados os resultados e discussão, por meio de tabelas e gráficos o panorama mundial sobre a Covid-19 e seu impacto sobre a população idosa, bem como a análise dos pactos em defesa da saúde da população idosa para o caso brasileiro. 


\section{REVISÃO TEÓRICA}

\section{Medidas de combate à propagação da covid-19}

Divergências entre a adoção do isolamento horizontal e/ou vertical passaram a ser amplamente debatidas (a partir das experiências de países severamente afetados) influenciando a tomada de decisões. Entretanto, apesar das divergências, o distanciamento social (total ou parcial) tem sido comum, tanto como medida de saúde pública, quanto de contenção de sua propagação. De acordo com o Ministério da Saúde brasileiro, diante do cenário de pandemia, podem ser adotadas três medidas de isolamento social: a) Distanciamento Social Ampliado (DSA), também chamado de Isolamento Horizontal, b) Distanciamento Social Seletivo (DSS) ou Isolamento Vertical e Bloqueio Total (lockdown).

Sem dúvida, "o isolamento horizontal tem maior potencial para conter a epidemia, pois, ao isolar um número maior de pessoas, gera-se uma dificuldade para a transmissão do coronavírus" (GOMES, 2020). Medidas de isolamento horizontal foram implementadas especialmente para proteger a população de maior risco: idosos e pessoas com comorbidades como câncer, hipertensão, diabetes e doenças cardiovasculares (MESA et al., 2020). Ao considerar que a Covid-19 espalha-se rapidamente por meio da transmissão de fluídos corporais, apertos de mãos, conversas próximas, toques em objetos contaminados e a falta de higienização das mãos, eleva-se o número de casos, ou seja, mais pacientes coexistem no mesmo intervalo de tempo e espaço, e com isso, há uma sobrecarga do sistema de saúde, sendo impossível dar suporte ao atendimento das demandas de casos graves e, consequentemente, da realização de exames em todos os pacientes com sintomas suspeitos (GOMES, 2020).

Montemerli (2020) menciona o fato de que a Covid-19 é provocada por um vírus com uma incubação totalmente assintomática, que pode atingir até 14 dias, e calcula-se que $80 \%$ das pessoas contagiadas não apresentem quaisquer sintomas relevantes e permanecem a condução de vida normal. Esse vírus apresenta todas as caraterísticas mais temidas pelos epidemiologistas, mas a nota mais dramática é o percentual de difusão. $\mathrm{O}$ vírus se expande rapidamente e aproximadamente $10 \%$ dos doentes desenvolvem pneumonia viral intersticial bilateral, necessitando de intubação com respiradores artificiais que permitam a ventilação mecânica. Se esses $10 \%$ dos pacientes são mais que as vagas disponíveis nas Unidades de Terapias Intensivas (UTIs), sendo, portanto, superiores ao número de respiradores, gera-se um colapso no sistema de saúde.

Seguindo este raciocínio, diversos países adotaram medidas de isolamento social, alguns imediatamente após o diagnóstico do primeiro caso da Covid-19. Foi o caso da Alemanha, Coreia do Sul e Nova Zelândia que passaram a realizar testes em massa na população para detectar o vírus em seu estágio inicial e, com isso, isolar as pessoas infectadas para conter a propagação. Em outros países, as medidas vieram tardiamente, a partir da implementação de isolamento social rigoroso já com elevado número de casos diagnosticados, como por exemplo Itália, Espanha e EUA. A Argentina, vizinha do Brasil, adotou medidas de quarentena obrigatória e se tornou referência no combate à doença na América do Sul.

A partir de 23/03/2020, o Brasil passou a adotar medidas de isolamento social mais rigorosas com a portaria do Ministério da Saúde e, posteriormente, a partir de decisões dos Estados e municípios, os quais 
decretaram restrições ao fluxo de pessoas com o intuito de evitar aglomerações, fechamento de comércio e controle de fronteiras.

Um modelo estatístico criado em uma pesquisa da Universidade Federal de Minas Gerais (UFMG) em parceria com a Universidade de Harvard e o Ministério da Saúde analisou três cenários para todos os estados brasileiros. O primeiro, otimista, com índice de contaminação de 0,5\% da população (considerando pacientes testados e confirmados); um moderado com contaminação de $1 \%$ e, por fim, a pessimista, com índice de contaminação de $2 \%$. No cenário otimista, em todos os estados, os leitos serão esgotados em maio (exceção do Distrito Federal). No cenário moderado, todos os estados, sem exceção, terão seus leitos esgotados antes de maio. No cenário pessimista, entre 27 de abril e 11 de maio, todos os leitos de UTI serão ocupados, com exceção de Acre, Rondônia, Roraima e Distrito Federal que teriam também seus leitos comuns ocupados. Os pesquisadores concluem que há duas formas de mitigar as previsões do modelo: a primeira é aumentar a infraestrutura do sistema de saúde, com leitos, pessoal e insumos (difícil no curto prazo); a segunda, a mais eficiente e viável, é o isolamento horizontal, pois com ele reduz-se a taxa da curva de transmissão e o achatamento da curva de contaminados e, consequentemente, a demanda por leitos de internação (ALMEIDA et al., 2020).

\section{METODOLOGIA}

A pesquisa traz inicialmente um panorama sobre o objeto de estudo que é a análise da evolução da Covid-19 e a elevada incidência de óbitos sobre as pessoas idosas. Este universo de estudo deve ser focado para o entendimento da defesa do isolamento horizontal. As fontes e dados são secundários oriundos de relatórios, boletins epidemiológicos nacionais e internacionais, Ministério da Saúde, órgãos e institutos de pesquisas públicos e privados, Instituto Brasileiro de Geografia e Estatística, Constituição Federal, projetos de leis de proteção ao idoso, etc.

O tratamento e método de análise de dados concentraram-se no âmbito exploratório com dois tipos de técnicas de pesquisa: a primeira é bibliográfica que busca informações em diferentes fontes de pesquisas com enfoque nas medidas utilizadas no combate ao coronavírus, dentre eles o isolamento horizontal vis-àvis o uso de periódicos que tratam o tema. A segunda técnica de pesquisa é de natureza quantitativa com uso dados de vários institutos e órgãos públicos e privados com o intuito de realizar uma análise descritiva de dados secundários de relatórios e boletins epidemiológicos que retratam o número de pessoas diagnosticadas pela doença, óbitos, recuperados, fazendo-se um recorte por faixa etária.

Trata-se, portanto, de um estudo de evolução temporal, tendo como área de investigação os países que se tornaram o epicentro da Covid-19. Analisou-se o universo de óbitos da população residentes na Itália, Espanha, Estados Unidos e Brasil, o que permite projetar qual o perfil das mortes e qual faixa etária está mais suscetível de contrair a doença e consequentemente, vir à óbito.

Informações para o Brasil foram obtidos nos Boletins epidemiológicos do Centro de Operações de Emergência em saúde Pública/Doença pelo Coronavírus 2019 (COE-COVID19) do Ministério da Saúde. Para a Itália a coleta foi feita no site do Epicentro (Epidemiologia para a saúde pública do Istituto Superiore di Sanità 
nos relatórios 'Características dos pacientes com COVID-19 morrendo na Itália'. Na Espanha os dados foram obtidos no Instituto de Saúde Carlos III (ISCIII) nos 'Informes sobre la situación de COVID-19 en España'. E por fim, nos Estados Unidos da América (EUA) os dados foram disponibilizados pelo Center for Disease Control and Prevention (CDC), a partir do National Center for Health Statistics (NCHS) em seus 'Dados e recursos sobre óbitos' associados ao COVID-19.

O número de mortes foi coletado com base nos atestados de óbito, que são a fonte mais confiável de dados e contêm informações não disponíveis em nenhum outro lugar, incluindo condições comórbidas, raça e etnia e local da morte. Para fins de interpretação dos dados, a contagem provisória de óbitos fornece uma imagem mais completa e precisa das vidas perdidas para o COVID-19.

Foram calculados coeficientes de mortalidade por faixa etária e a variação proporcional da mortalidade ao longo do período analisado. O cálculo foi realizado com base na mortalidade da primeira semana de coleta e, recorrentemente, ao longo das semanas de incidência de casos e óbitos relacionados a Covid-19, considerados na equação variação proporcional $=$ (№ de óbitos $\mathrm{t} 2 / \mathrm{n}$ ㅇ de óbitos $\mathrm{t} 1$ ) $-1 \times 100$, no qual t2 representa o número de óbitos no tempo atual e t1 o número de óbitos no tempo anterior. 0 peso de cada faixa etária também é significativo nesta análise, sendo calculado a partir da equação \% faixa etária = (№ de óbitos por faixa etária/no total de óbitos) x 100. Para a análise da evolução temporal dos coeficientes de mortalidade, foram estimadas variações temporais simples (t2/t1) de acordo com a base de dados disponível com construção de tabelas e gráficos.

\section{RESULTADOS E DISCUSSÃO}

\section{Panorama das informações sobre a covid-19 e seus efeitos sobre a população idosa}

O primeiro relato de contágio da Covid-19 em humanos foi registrado em dezembro de 2019 na China. Os registros relacionados ao número de novos casos, mortes e recuperados sofreram significativa evolução ao longo dos últimos meses. De acordo com a OMS, ao final de janeiro, cerca de $98 \%$ dos casos estavam concentrados na China e em meados de abril, mais precisamente $30,8 \%$ dos casos confirmados, concentravam-se nos EUA, seguido por Espanha e Itália, com respectivamente 8,6\% e 7,8\%.

Segundo dados do Worldometers (Tabela 1), os números de casos da Covid-19, na data de 28 de abril de 2020 , representam $83,17 \%$ para um conjunto de 16 países. Este recorte mostra que a maioria dos casos está concentrada nos EUA (32,72\%) e países da Europa (36,37\%). Na Europa 29,61\% dos casos concentramse em torno de 5 países: Espanha (7,53\%), Itália (6,46\%), França (5,38\%), Alemanha (5,15\%) e Reino Unido (5,09\%). Completando a relação temos o Irã (3,0\%), China (2,69\%), Brasil (2,19\%) e Canadá (1,57\%). A Tabela 1 também mostra onde os novos casos tem avançado com certa rapidez, como é o caso do Peru que relatou 112.261 casos ( $3,64 \%$ do total), Bélgica com 47.334 casos ( $1,53 \%$ do total), Índia com 29.451 casos (0,95\% do total) e Suíça com 29.264 casos (0,95\% do total). Acredita-se que a quantidade de novas pessoas infectadas deve se expandir consideravelmente nos próximos meses, uma vez que a Covid-19 já foi diagnosticada em 212 países e territórios ao redor do mundo, muitos em seu estágio inicial de contágio. 
Tabela 1: Número de casos, mortes e recuperados para a Covid-19, até 28 de abril de 2020.

\begin{tabular}{|c|c|c|c|c|c|c|c|c|c|}
\hline Ranking & Países & $\begin{array}{c}\text { Total de } \\
\text { Casos }\end{array}$ & $\begin{array}{c}\text { Total } \\
\text { Mortes }\end{array}$ & $\begin{array}{c}\text { Total } \\
\text { recuperados }\end{array}$ & $\begin{array}{c}\text { Mortes/1 } \\
\text { Milhão }\end{array}$ & $\begin{array}{c}\text { Testes/1 } \\
\text { milhão }\end{array}$ & $\begin{array}{c}\% \\
\text { casos }\end{array}$ & $\begin{array}{c}\% \\
\text { mortes }\end{array}$ & População \\
\hline- & Mundo & 3.084 .740 & 212.516 & 934.403 & 27,3 & - & - & - & - \\
\hline 1 & USA & 1.010 .507 & 56.803 & 139.162 & 172 & 17.211 & 32,76 & 26,73 & 330.811 .717 \\
\hline 2 & Espanha & 232.128 & 23.822 & 123.903 & 510 & 28.779 & 7,53 & 11,21 & 46.753 .049 \\
\hline 3 & Itália & 199.414 & 26.977 & 66.624 & 446 & 29.600 & 6,46 & 12,69 & 60.470 .230 \\
\hline 4 & França & 165.842 & 23.293 & 45.513 & 357 & 7.103 & 5,38 & 10,96 & 65.259 .581 \\
\hline 5 & Alemanha & 158.768 & 6.136 & 117.400 & 73 & 24.738 & 5,15 & 2,89 & 83.757 .965 \\
\hline 6 & UK & 157.149 & 21.092 & $\mathrm{~N} / \mathrm{D}$ & 311 & 10.605 & 5,09 & 9,92 & 67.851 .047 \\
\hline 7 & Peru & 112.261 & 2.900 & 33.791 & 34 & 10.895 & 3,64 & 1,36 & 84.247 .422 \\
\hline 8 & Rússia & 93.558 & 867 & 8.456 & 6 & 21.511 & 3,03 & 0,41 & 145.928 .485 \\
\hline 9 & Irã & 92.584 & 5.877 & 72.439 & 70 & 5.269 & 3,00 & 2,77 & 83.883 .203 \\
\hline 10 & China & 82.836 & 4.633 & 77.555 & 3 & - & 2,69 & 2,18 & 1.439.323.776 \\
\hline 11 & Brasil & 67.446 & 4,603 & 31.142 & 22 & 1.597 & 2,19 & 0,00 & 212.409 .786 \\
\hline 12 & Canadá & 48.500 & 2.707 & 18.268 & 72 & 19.440 & 1,57 & 1,27 & 37.709 .091 \\
\hline
\end{tabular}

Os dados disponibilizados pela OMS e Worldometers possibilitam constatar a velocidade em que o vírus se espalha e contamina a população mundial. Nos EUA, por exemplo, o primeiro caso diagnosticado ocorreu em 21 de janeiro, no estado de Washington, no Condado de Snohomish. Em 30 de janeiro, o país confirmou o primeiro caso de transmissão entre pessoas dentro de seu território. Já no dia 30 de março, o quantitativo alcançava 165.053 pessoas e, apenas quinze dias depois, 648.000 casos confirmados para Covid19. Neste último período, observou-se um crescimento de $392 \%$ e uma média de 31.480 novos casos. Atualmente o país possui 1.725.275 casos e 100.572 mortes, conforme dados da tabela 2. O Brasil que apresentava pequena parcela de casos, em um mês é o segundo país com o maior número de casos $(6,91 \%$ do total) e elevado número de óbitos (6,98\% do total). Neste meio tempo, o epicentro saiu da América do Norte, e direcionou-se para a América do Sul.

Outro ponto importante na pauta das discussões e que se relaciona diretamente às medidas de isolamento é a escassez da quantidade de testes realizados. A Tabela 1 mostra que o Brasil realizou apenas 1.597 testes para cada um milhão de habitantes (em um mês este valor subiu para 4.104 testes). Entretanto, países como os EUA já realizaram 15,2 milhões de testes, Espanha 3,5 milhões, Itália 3,4 milhões, Alemanha 3,59 milhões de testes e a Rússia 9,1 milhões. Vale ressaltar que as realizações de testes em massa foram extremamente relevantes na contenção dos avanços da Covid-19, uma vez que é possível diagnosticar a doença, isolar os indivíduos e realizar o tratamento adequado. No Brasil, em um mês (Tabela 2), este número pouco se alterou, comparativamente aos demais países, o que levanta questionamento sobre a existência de subnotificações. 
Tabela 2: Número de casos, mortes e recuperados para a Covid-19, até 27 de maio de 2020.

\begin{tabular}{|c|c|c|c|c|c|c|c|c|c|c|}
\hline Ranking & Países & $\begin{array}{l}\text { Total de } \\
\text { Casos }\end{array}$ & $\begin{array}{l}\text { Total } \\
\text { Mortes }\end{array}$ & $\begin{array}{l}\text { Total } \\
\text { recuperados }\end{array}$ & $\begin{array}{l}\text { Mortes/1 } \\
\text { Milhão }\end{array}$ & $\begin{array}{l}\text { Total de } \\
\text { testes }\end{array}$ & $\begin{array}{l}\text { Testes/1 } \\
\text { milhão }\end{array}$ & População & $\%$ casos & $\begin{array}{l}\% \\
\text { mortes }\end{array}$ \\
\hline- & Mundo & 5.678 .146 & 351.654 & 2.428 .132 & 45,1 & - & - & - & - & - \\
\hline 1 & EUA & 1.725 .275 & 100.572 & 479.969 & 304 & 15.207 .234 & 46.951 & 330.811 .717 & 30,38448 & 28,60 \\
\hline 2 & Brasil & 392.360 & 24.549 & 158.593 & 116 & 735.224 & 4104 & 212.409 .786 & 6,91 & 6,98 \\
\hline 3 & Rússia & 362.342 & 3.807 & 131.129 & 26 & 9.160 .590 & 62.774 & 145.928 .485 & 6,38 & 0,00 \\
\hline 4 & Espanha & 283.339 & 27.117 & 196.958 & 580 & 3.556 .567 & 76.071 & 46.753 .049 & 4,99 & 7,71 \\
\hline 5 & $\begin{array}{l}\text { Reino } \\
\text { Unido }\end{array}$ & 265.227 & 37.048 & $\mathrm{~N} / \mathrm{D}$ & 546 & 3.681 .295 & 54.255 & 67.851 .047 & 4,67 & 10,54 \\
\hline 6 & Itália & 230.555 & 32.955 & 144.658 & 545 & 3.482 .253 & 58.540 & 60.470 .230 & 4,06 & 9,37 \\
\hline 7 & França & 182.722 & 28.530 & 65.879 & 437 & 1.384 .633 & 21.217 & 65.259 .581 & 3,22 & 8,11 \\
\hline 8 & Alemanha & 181.288 & 8.498 & 162.000 & 101 & 3.595 .059 & 42.922 & 83.757 .965 & 3,19 & 2,42 \\
\hline 9 & Turquia & 158.762 & 4.397 & 121.507 & 52 & 1.853 .754 & 22.239 & 84.247 .422 & 2,80 & 1,25 \\
\hline 10 & Índia & 150.793 & 4.344 & 64.277 & 3 & 3.126 .119 & 2.267 & 1.378 .641 .054 & 2,66 & 0,00 \\
\hline 11 & Irã & 139.511 & 7.508 & 109.437 & 90 & 837.090 & 9.979 & 83.883 .203 & 2,46 & 2,14 \\
\hline 12 & Peru & 129.751 & 3.788 & 52.906 & 115 & 840.922 & 26597 & 32.924 .686 & 2,29 & 1,08 \\
\hline
\end{tabular}

Fonte: Adaptado de Worldometers.

Montemerli (2020) relata o avanço do Coronavírus na Itália e revela que o primeiro caso de transmissão secundária registrado no país ocorreu no dia 21 de fevereiro em Codogno, município a sudoeste de Milão na província de Lodi, na Lombardia, região norte da Itália (FARIAS, 2020). Os dados do Worldometers mostram que os números de casos na Itália cresceram vertiginosamente, atingindo seu pico em 21 de março, com 6.557 novos casos, mantendo patamares elevados (mas em declínio) até 30 de abril, quando foram diagnosticados 1.872 novos casos e, no fim do mês de maio (27/05), registrou 397 novos casos, totalizando 230.555 casos confirmados. Na Espanha, apesar do crescimento acelerado no número de casos, que alcançou 8.271 novos casos em 26 de março, mantendo-se em patamares bastante elevados, desde 31 de março, houve uma redução significativa dos novos casos. Em 30 de abril foram diagnosticados 2.740 e 859 novo casos em 27 de maio, totalizando 283.339 casos. Esses dois países já iniciaram o processo de flexibilização do isolamento social.

Observa-se, que o quantitativo de mortes é elevado e alarmante, principalmente para os países europeus (que apresentam os maiores percentuais de população idosa). A Bélgica é o país que apresentou maior taxa de mortalidade, para cada milhão de habitantes, com 633 óbitos, seguida pela Espanha com 510 óbitos, Itália 446 óbitos, França com 357 óbitos e Reino Unido com 311 óbitos, conforme dados na Tabela 1. Estes números, aliados ao quantitativo de indivíduos em caso crítico, devem inflar ainda mais estas estatísticas. No dia 27 de abril de 2020, foram registradas 7.062 novas mortes (e 5.081 em 30 de abril), sendo 2.804 (2.201 em 30 de abril) apenas nos EUA. No fim de maio, tem-se um total de 353.042 mortes, sendo que somente nos EUA foram registrados 100.745 óbitos.

Entre os países que tiveram elevados casos de Covid-19, e aqui são analisados os dados nos períodos 
de maior incidência da doença e dos óbitos, observa-se que, na Itália, o pico foi no dia 27 de março, com 9.191 óbitos, números em declínio, pois, em 30 de abril, registrou-se 285 óbitos. Na Espanha o número de mortes também registrou queda. O país atingiu seu maior quantitativo em 02 de abril de 2020 com 961 óbitos e, no dia 30 de abril, caiu para 268 óbitos. Na França, que já havia registrado 1.438 óbitos em 15 de abril (sendo que em 7 de abril e 9 de abril notificou-se 1.417 e 1.341 mortes, respectivamente), no dia 30 de abril, houve uma considerável queda, com 289 óbitos. Caso mais preocupante é do Reino Unido que apesar de registrar um pico no dia 10 de abril com 980 mortes, tem oscilado em torno de uma média elevada de 761 óbitos (no período de 11 dias). No dia 21 de abril, o Reino Unido somou 828 óbitos; no dia 30 de abril, 674 óbitos e atingiu, em 26 de maio, 2.004 óbitos, em um total de 37.048 mortes pela Covid-19. Atualmente é o primeiro país com mais mortes na Europa.

No Brasil, dados de 27 de maio, do Ministério da Saúde, confirmaram 392.360 casos. O histórico de novos casos mostra que o país atingiu o pico no dia 20 de maio, onde foram registrados 21.472 novos casos e, um dia após, contabilizou o maior número de mortes, qual seja 1.188. As informações denotam grande preocupação uma vez que o número de casos tem aumentado consideravelmente desde então. Em um mês, o país alçou para a segunda posição entre os países com casos confirmados da Covid-19 e mais de 50\% estão concentrados na região Sudeste, principalmente no estado de São Paulo - região e estado mais populoso. Contudo, a doença avança rapidamente para o Norte e Nordeste do país. Pelos dados do Worldometers, observa-se que o Brasil levou cerca de 40 dias para registrar as primeiras 1.000 mortes, depois disto foram necessários 7 dias, depois 5 dias e agora, na última semana de abril, foram apenas 3 dias para registrar mais 1.000 óbitos. Tais estimativas comprovam que o país está se aproximando do ponto em que registrará o maior número de casos e, consequentemente, o de óbitos.

Nos EUA, os dados do Centro de Controle e Prevenção de Doenças (CDC) mostram que do total de indivíduos que contraíram Covid-19, o maior percentual se encontra na faixa entre 18 e 64 anos (72,52\%) e os indivíduos entre 18 e 44 anos, representam 35,96\%; os de 45 a 64 anos (36,55\%); os de 65 a 74 anos $10,66 \%$ e de 74 anos ou mais $12,09 \%$. Tais informações corroboram o estudo do próprio CDC, de 18 de março de 2020, o qual apontava que nos casos de internação pela Covid-19, o maior percentual encontrava-se na faixa entre 20 e 54 anos, população de jovens e adultos. Embora esta parcela significativa da população contraia a doença, com probabilidade de avançarem para a situação grave, com necessidade de hospitalização, a maior parte dos casos de óbito estão localizadas entre os mais idosos. No caso da Covid-19 quanto mais se avança na faixa etária, maior é a probabilidade de fatalidade da doença.

Em uma análise mais detalhadas nos informativos epidemiológicos dos centros de controle e prevenção de doenças, para um conjunto de quatro países (Itália, Espanha, EUA e Brasil), traçou-se o perfil dos indivíduos que vieram a óbito em decorrência da Covid-19. Nos EUA, para os dados de óbitos (devidamente registrados no Centro Nacional de Estatísticas de Saúde, por meio de atestados de óbitos, codificado no código CID-10 U07.1.), é possível comprovar o impacto sobre as faixas etárias (Figura 1). Embora o número de óbitos tenha se elevado para todos os recortes, o peso dos óbitos se concentra entre 55 e 84 anos (ou mais), ou seja, 91\% dos óbitos. Ao filtrar a análise nos indivíduos acima de 65 anos, o 
percentual atinge 77,6\% dos óbitos e, dos acima de 75 anos, 55,37\%. Os dados são alarmantes e, por isso, há a defesa do isolamento social, uma vez que os riscos nos casos de Covid-19 entre pessoas nos Estados Unidos aumentam com a idade. A taxa de crescimento dos óbitos, para os 4 dias de observações, aponta um percentual de 89\%, saindo de um patamar de 6.930 óbitos em 13 de abril para 13.133 em 17 de abril de 2020 .

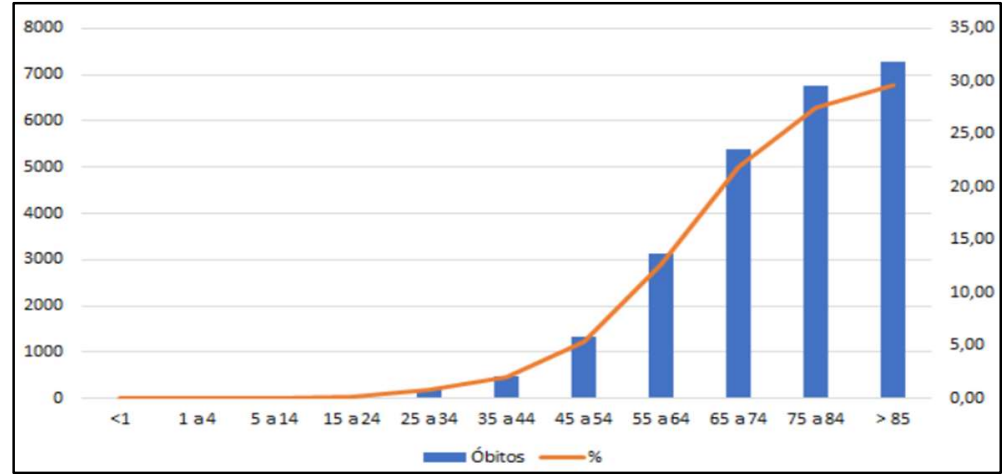

Figura 1: Número e percentual de óbitos por faixa etária nos EUA, 2020. Fonte: CDC (2020).

O site Poder360 publicou um artigo comparando a faixa etária dos mortos no Brasil, Itália, Espanha e EUA e mostrou que a população mais vulnerável é a da faixa etária acima dos 60 anos. Os mais jovens, entretanto, têm presença nas hospitalizações e ocupam leitos que podem faltar aos pacientes com Covid-19 ou outras doenças. Por isso, o contágio de pessoas em outras faixas etárias pode também impactar na mortalidade dos idosos. Outro assunto delicado e sem estatísticas é em relação a preferência tácita no salvamento de vidas de pacientes com Covid-19, sendo a vida do idoso preterida em muitas situações pela vida do mais jovem, com a justificativa de que esse terá mais chances de sobrevivência. Sistematicamente, em países onde se iniciou tardiamente o isolamento social, os profissionais da saúde relataram sobre o árduo peso da escolha entre a vida de um em detrimento da de outro.

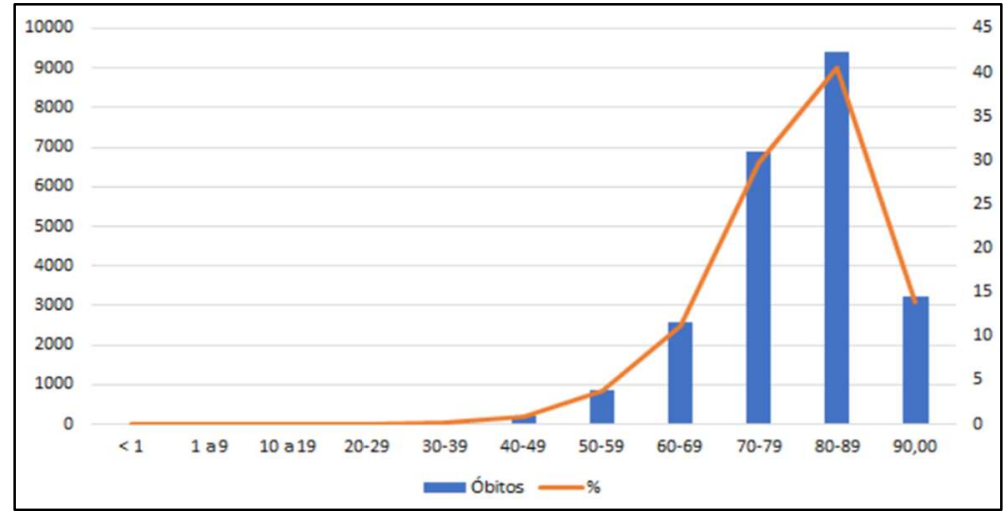

Figura 2: Número e percentual de óbitos por faixa etária na Itália, 2020. Fonte: Instituto Nacional de Estatística (ISTAT) (2020).

A análise dos boletins epidemiológicos na Itália conduz às mesmas considerações, qual seja, concentração dos óbitos na população idosa. De acordo com a Figura 2, nesse país, cerca de 95,1\% das mortes estão na faixa entre 60 anos e 90 anos ou mais, com elevado percentual nas faixas entre 80 e 89 anos (40,52\%) e entre 70 e 79 anos (29\%). Observa-se também uma taxa extremamente baixa de óbitos entre jovens e adultos (de 20 a 49 anos) de 1,1\%, reforçando a hipótese de que a população idosa é a mais atingida por 
óbitos.

De forma bastante semelhante, a Espanha apresentou 95\% dos óbitos entre os indivíduos com idade acima de 60 anos. No entanto, a faixa etária superior aos 80 anos representa $60,4 \%$ destes óbitos, enquanto entre 70 e 79 anos representam 26\% dos óbitos (Figura 3). Nesse país, entre 60 e 69 anos são de 8,8\% e, entre jovens e adultos (de 15 a 49 anos), apenas 1,56\%.

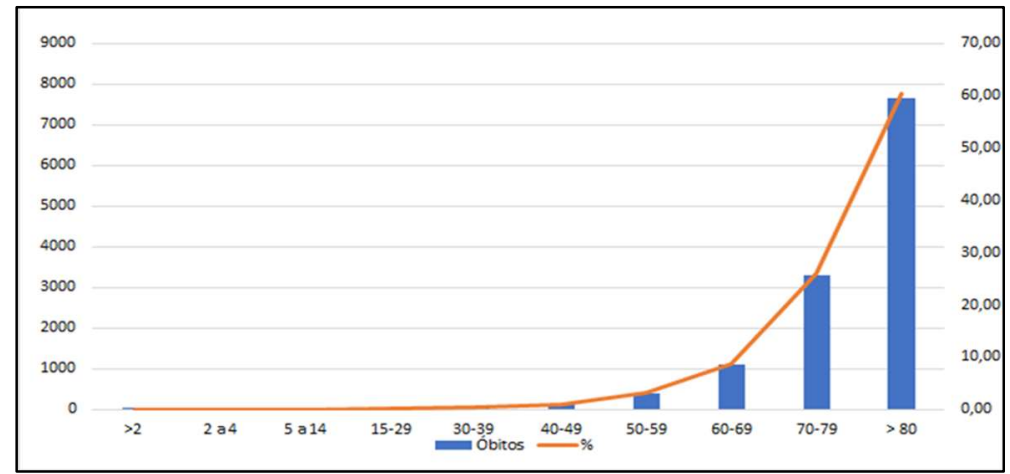

Figura 3: Número e percentual de óbitos por faixa etária na Espanha, 2020.

No Brasil, acredita-se que o pico da doença ainda não foi atingido e pode ser que este fato faça a curva de óbitos se assemelhar a uma distribuição normal. Caso se mantenha nesta inclinação, pode-se supor que o isolamento social, mesmo diante de diversas críticas, apresentou resultados positivos. De acordo com a Figura 4, o percentual é mais disperso, atinge mais faixas etárias e concentra-se entre os indivíduos de 50 a 89 anos, o que corresponde a $80 \%$ do número total de óbitos registrados. Entre os da faixa etária de 0 a 50 anos, este percentual é de $15 \%$. Contudo, para as pessoas acima de 60 anos, o percentual é muito elevado e atinge o patamar de $69,3 \%$.

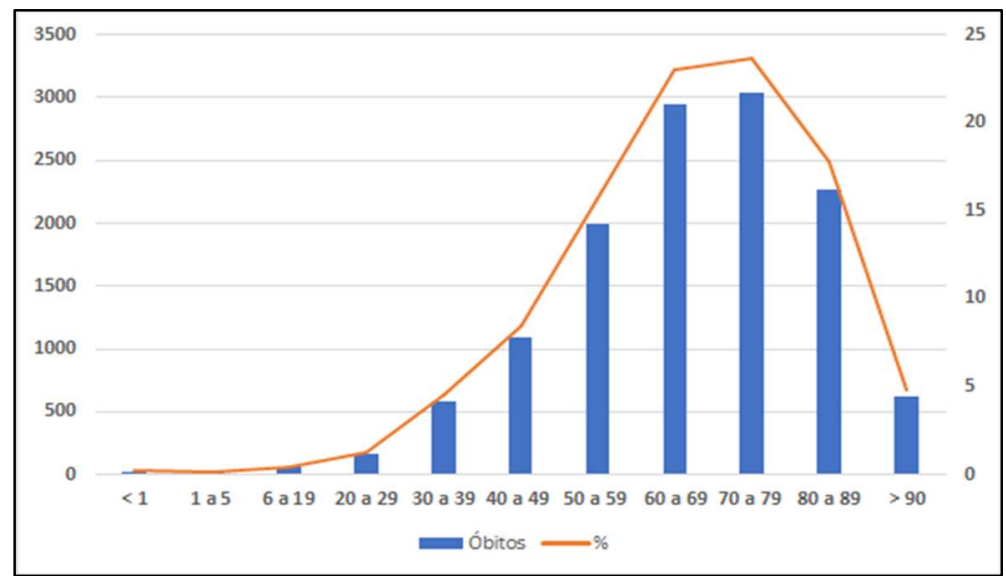

Figura 4: Número e percentual de óbitos por faixa etária no Brasil por Covid-19 de 17-23 de maio 2020. Fonte: Ministério da Saúde (BRASIL, 2020).

Em suma, em decorrência do perfil da população, das condições climáticas e das medidas adotadas para conter a disseminação do vírus, é esperado que os resultados relacionados aos óbitos apresentem características distintas dos países do Hemisfério Norte, se mantidas as medidas rigorosas de isolamento social. No entanto, no Brasil, diversos estados e o Distrito Federal, em meio ao aumento vertiginoso de novos casos e óbitos, passaram a discutir formas de flexibilizar as medidas de isolamento horizontal, regulando a abertura gradativa de várias atividades econômicas. Esta flexibilização pode aumentar a incidência de novos 
casos e, consequentemente, aproximar a realidade do país àqueles que já passaram pelo surto da doença.

\section{Pactos em defesa da saúde da população idosa}

Historicamente, o processo de envelhecimento foi visto com um viés negativo e com preconceitos, como uma fase de declínio e de perdas. Fortemente influenciado pela cultura e contextos de vida, o idoso é frequentemente tratado com desprezo, de forma infantilizada e paternalista, além de maus-tratos físicos, psicológicos e financeiros nos estabelecimentos de saúde e em locais de trabalho (TODD, 2005). Esse quadro de preconceito pode implicar danos para a qualidade de vida dos idosos e sua inserção na sociedade, já que os avanços da medicina têm permitido às pessoas viverem mais, com menos doenças e déficits físicos. Segundo Paula et al. (2017), malgrado os idosos sejam vulneráveis e discriminados, a sociedade e o Estado têm se atentado para essa categoria, possivelmente porque uma grande maioria da população, um dia, fará parte desse grupo social.

Na perspectiva da necessidade de fortalecimento de políticas públicas para os idosos, em 1982, surgem a I Assembleia Mundial sobre o Envelhecimento e a elaboração do Plano de Ação de Viena sobre Envelhecimento com destaque para o primeiro grande marco do estabelecimento dessas políticas públicas, direcionando-se às preocupações com os direitos humanos. O segundo grande marco ocorreu na Assembleia da ONU de 1992, tendo sido aprovada a Proclamação sobre o Envelhecimento e o slogan "Uma sociedade para todas as idades" para o ano de 1999, marcado como o Ano Internacional dos Idosos. Por fim, o terceiro grande marco ocorreu com a adoção de um Plano Internacional para o Envelhecimento no Século XXI realizada pela II Assembleia Mundial das Nações Unidas sobre o Envelhecimento, em Madri, na Espanha. Portanto, surgem os marcos do estabelecimento de políticas públicas para as pessoas idosas no mundo, com grandes preocupações com os direitos humanos (MARTINS et al., 2018).

No Brasil, apesar das iniciativas com a Lei Eloy Chaves, de 1923, e de outros avanços observados na década de 1970, a proteção legislativa e tais políticas públicas ocorreram, como relevante marco, por meio da Constituição Federal de 1988 (BRASIL, 1988). A Constituição trouxe o dever da família, da sociedade e do Estado em assegurar a proteção integral ao idoso, abrangendo, dentre outros, o direito à vida, dignidade, bem-estar e participação social. A Constituição também garantiu à essa população a gratuidade dos transportes coletivos, além de um benefício assistencial de um salário mínimo aos que não tiverem meios de prover o próprio sustento, dentre outras prerrogativas em razão da idade. Nesse sentido, foi instituída a Política Nacional do Idoso (PNI) (LEI n. 8.842) (BRASIL, 1994), resultante de reivindicações e debates da sociedade brasileira, com a participação de pessoas idosas, pesquisadores, profissionais da área de gerontologia e geriatria e de instituições.

No decorrer da década de 2000, o Estado reforçou o seu pacto de proteção ao idoso. Em 2002, foi criado o Conselho Nacional dos Direitos do Idoso (CNDI), que possui importante papel na promoção desses direitos ao elaborar diretrizes para a formulação e implementação da PNI. Em 2003, como grande marco regulatório de proteção aos direitos dessa categoria, foi sancionado o Estatuto do Idoso (BRASIL, 2003). Esse diploma legal teve o mérito de sistematizar as garantias e direitos da pessoa idosa, além de ter criado e 
reforçado os já existentes, como as medidas de proteção ao idoso vítima de violência. O Estatuto trouxe um sistema de instituições e órgãos voltados para a proteção da classe e prerrogativas do idoso no Poder Judiciário, Defensoria Pública, Ministério Público e Polícia Civil. Ainda em 2003, foi criado o PNDH-3, Programa Nacional de Direitos Humanos, que intensificou, dentre outras ações, a necessidade de inserir o idoso na sociedade, humanizar o seu tratamento e atendimento de saúde, combater e prevenir a violência contra essa categoria.

Em 2004 foi aprovada a Política Nacional de Assistência Social (PNAS), regida por vários princípios, dentre os quais a universalização dos direitos sociais, a dignidade e a autonomia do cidadão, o direito a benefícios e serviços de qualidade, além de defender a igualdade de direitos (BRASIL, 2004). Em 2005 iniciase o Plano de Ação para o Enfrentamento da Violência contra a Pessoa Idosa, sendo um esforço conjunto entre o Governo Federal, o Conselho Nacional dos Direitos dos Idosos e os movimentos sociais (BRASIL, 2005). Posteriormente esse Plano desenvolveu o Manual de Enfrentamento à Violência contra a Pessoa Idosa que trouxe as situações de violência e estratégias de ação e prevenção (BRASIL, 2014).

Em 2006, foi criada a Política Nacional do Idoso (PNSI), pela Portaria №. 2.528 (BRASIL, 2006), que definiu ações diversas em vários setores, como educação, cultura, lazer dentre outros em prol do idoso. Neste mesmo ano destaca-se a instituição do dia 1 o de outubro como o Dia Nacional do Idoso (BRASIL, 2006). Em 2013 foi estabelecido o Compromisso Nacional para o Envelhecimento Ativo, favorecendo o diálogo interministerial e de outros órgãos e entidades públicas envolvidos nessa implementação.

Em 2018, foi instituída a Estratégia Brasil Amigo da Pessoa Idosa (Decreto n. 9.328) (BRASIL, 2018). A Estratégia objetiva levar qualidade de vida às pessoas idosas e promover o envelhecimento ativo, saudável, cidadão e sustentável. A Estratégia reúne ações dos setores governamentais, organismos internacionais e instituições públicas e privadas para atingir os seus objetivos, incentivando o incremento de uma rede de proteção à pessoa idosa nos municípios, criando oportunidades para inovar na gestão pública e tornar a pessoa idosa como protagonista nos processos políticos. Posteriormente, em 2019, foi atualizada a Estratégia por meio do Decreto n. 9.921, 2019.

Ressalta-se que a adesão dos municípios à Estratégia é voluntária. Segundo Reis et al. (2020), o processo de adesão pode ocorrer tanto pelo fluxo de problemas, em relação a questão do idoso, quanto pelo fluxo de se buscar soluções. A estratégia ainda é incipiente nos municípios, mas que tem de alguma forma levantado a questão do idoso como um problema público, e destacando a necessidade que essa parcela tem de ser escutada nas ações que são desenvolvidas para atendê-los (REIS et al., 2020).

Não é difícil concluir, portanto, que há um pacto firmado pelo Estado e sociedade civil brasileira, de proteção e defesa à vida, à dignidade e à saúde do Idoso. Todos esses instrumentos legais trazem de forma clara a intensificação do processo de envelhecimento e a forma como o idoso deve ser incorporado e protegido no seio social. É ínsito à idade avançada, contudo, problemas de saúde, como doenças cardíacas, cerebrovasculares, diabetes, pneumonia entre outras. Os idosos são, portanto, vulneráveis, dado o grau de suscetibilidade destas pessoas em adquirir problemas de saúde (BERTOLOZZI et al., 2009). No Brasil, conforme dados do Instituto Brasileiro de Geografia e Estatística - IBGE (2017), os idosos correspondem a 
30,2 milhões de pessoas.

Portanto, ao se transpor esse resgate histórico e legislativo de proteção do idoso ao cenário de enfrentamento a Covid-19, evidencia-se a defesa pelo sistema de isolamento horizontal em detrimento do vertical. Ademais, as deficiências no isolamento vertical trazem um vertiginoso aumento no contágio que, por consequência, gera um maior risco de exposição dos idosos, sobretudo porque é inviável que todos estes se isolem totalmente, já que precisam frequentar espaços públicos essenciais, como supermercados e farmácias. Quer dizer, muitos idosos não residem sozinhos, mas com outras pessoas, não participantes do grupo de risco, e que frequentariam normalmente os espaços públicos. Por fim, a sobrecarga no Sistema de Saúde implicaria na demora no atendimento que poderia elevar o número de óbitos dessa categoria.

Em síntese, a possibilidade de isolamento vertical defendida pela Presidência da República e a Confederação Nacional das Indústrias implicaria em uma sentença de morte para muitos idosos, associada à vulnerabilidade da saúde dessa categoria e em razão do percentual de óbitos pela Covid-19 demonstrar uma alta concentração na faixa etária dos indivíduos com mais de 60 anos.

\section{CONCLUSÕES}

Como esperado, a Covid-19 se espalhou pelo mundo a partir de seu primeiro diagnóstico na província de Wuhan, na China e hoje atinge 213 países e territórios, totalizando 5.814 .418 casos, 357.856 mortes e 2.415.816 pessoas curadas até o dia 28 de maio de 2020. Em um mês, o número de novos casos aumentou $79,6 \%$ e uma elevação de $52,4 \%$ no número de óbitos. Estes se elevam dia após dia e transfere o epicentro da Covid-19 para outros continentes, saindo da Ásia, passando pela Europa, depois América do Norte e agora se direciona para a América do Sul. Embora tenha apresentado significativo crescimento em países como Rússia, Índia e México. Uma vez que a velocidade de contágio do vírus é muito rápida, as medidas de isolamento (vertical ou horizontal) não conseguem conter o seu avanço.

Diante deste cenário, muitos países adotam medidas, mais ou menos flexíveis, para conter a propagação da doença e evitar o colapso dos sistemas de saúde locais e, consequentemente, o óbito de pessoas. Essas medidas resumem-se na adoção de práticas não farmacológicas e isolamento social, enquanto ainda não se produz uma vacina para a Covid-19.

Observa-se que o número de casos concentra nos países do hemisfério norte, destacando-se os países que se tornaram epicentro da doença, como China, Itália, Espanha e EUA. Nesses países, as medidas adotadas conseguiram amenizar o contágio, mas não foram suficientes para evitar a elevada taxa de mortalidade, o que faz concluir quão rápida é a propagação do vírus. Ao adotar, antecipadamente, medidas de controle e testagem em massa, os resultados foram resultados positivos, com menos casos e óbitos, como por exemplo, as adotadas na Alemanha, Coréia do Sul e Nova Zelândia.

A análise dos dados dos boletins epidemiológicos, principalmente nos períodos de maior incidência da doença, possibilitou comprovar que nos países com número de casos elevados e, considerados na análise como epicentro da Covid-19, o percentual de óbitos concentra-se na faixa etária dos indivíduos com mais de 60 anos, e em muitos destes países, este percentual corresponde a mais de $90 \%$ do total de óbitos. 
Observa-se que as medidas de isolamento vertical adotadas por países como Itália, Espanha e EUA não amenizaram as mortes em decorrência da Covid-19 e pior, dada a característica de sua população, gerou efeitos negativos e significativos sobre os indivíduos de faixa etária elevada. Pode-se afirmar, a partir dos dados dos boletins epidemiológicos, que apresentam o balanço de mortes pela Covid-19 (devidamente comprovada por atestado de óbito), que na Itália e Espanha, a cada 100 óbitos, 95 ocorrem entre indivíduos de 60 anos ou mais. Esse número cai para 91 nos EUA e 69 no Brasil. Tais informações possibilitam traçar perspectivas alarmantes a partir da ampliação do contágio da Covid-19 e permite afirmar que as nações devem optar pelo modelo de isolamento horizontal. Tal opção permitirá, ao longo do tempo, dirimir o quantitativo de óbitos, principalmente, entre os idosos.

Claro está que essa escolha não é a que mais agrada aos governantes, que terão que sacrificar o desempenho econômico em detrimento a salvar vidas, decisões que envolvem análise de cenários de curto e longo prazo. Esse embate está sendo presenciado em diversos países e muitos, após decretarem isolamento social, flexibilizaram as medidas. Logo, pouco tempo depois, passaram a presenciar o aumento no número de casos. Por isso, flexibilizar não parece ser a melhor estratégia, pois países, como a Itália e EUA, que flexibilizaram o isolamento social, tiveram que retomá-lo de maneira mais rigorosa quando houve o aumento de casos de Covid-19. Ao observar a evolução do número de novos casos e óbitos, o Brasil parece seguir o mesmo caminho, relutando em entender as consequências da propagação desta doença e o que é pior, desconsiderando o que está acontecendo em outros países.

\section{REFERÊNCIAS}

ALMEIDA, J. F. F.; CONCEIÇÃO, S. V.; PINTO, L. R.; MAGALHÃES, V. S.; NASCIMENTO, I. J.; COSTA, M. P.; FARIA, H. P.; CAMPOS, F. C. C.. Previsão de disponibilidade de leitos nos estados brasileiros e Distrito Federal em função da pandemia de Covid-19. Belo Horizonte: UFMG, 2020.

BERTOLOZZI, M. R.; NICHIATA, L. Y. I.; TAKAHASHI, R. F.; CIOSAK, S. I.; HINO, P.; VAL, L. F. D.; PEREIRA, É. G.. Os conceitos de vulnerabilidade e adesão na Saúde Coletiva. Revista Esc. Enferm. USP, v.43, n.2, p.1326-1330, 2009.

BRASIL. Câmara dos Deputados. Propostas visam garantir proteção para idosos durante a pandemia de Covid-19. Brasília: Câmara dos Deputados, 2020.

BRASIL. Congresso Nacional. Plano de ação para o enfrentamento da violência contra a pessoa idosa. Brasília: Subsecretaria de Direitos Humanos, 2005.

BRASIL. Constituição da República Federativa do Brasil de 1988. Brasília: DOU, 1988.

BRASIL. Decreto n. 9.328, de 03 de abril de 2018. Institui a Estratégia Brasil Amigo da Pessoa Idosa, 2018.

BRASIL. Decreto n. 9.921, de 18 de julho de 2019. Consolida atos normativos editados pelo Poder Executivo federal que dispõem sobre a temática da pessoa idosa, 2019.

BRASIL. LEI n. 10.741, de 10 de outubro de 2003. Dispõe sobre o Estatuto do Idoso e dá outras providências. Brasília:
DOU, 2003.

BRASIL. LEI n. 11.433, de 28 de dezembro de 2006. Dispõe sobre o Dia Nacional do Idoso. Brasília: DOU, 2006.

BRASIL. LEI n. 8.842, de 04 de janeiro de 1994. Dispõe sobre a política nacional do idoso, cria o Conselho Nacional do Idoso e dá outras providências. Brasília: DOU, 1994.

BRASIL. Ministério da Mulher, da Família e dos Direitos Humanos. Manual de Enfrentamento à Violência contra a Pessoa Idosa. Brasília: MMFDH, 2014.

BRASIL. Ministério da Saúde. Boletim Epidemiológico Especial COE-Covid: semana epidemiológica 21 (17 a 23/05). 2020.

BRASIL. Ministério da saúde. Boletins Epidemiológicos. Brasília: MS, 2020.

BRASIL. Ministério de Saúde. Portaria n. 2.528 de 19 de outubro de 2006. Brasília: MS, 2016.

BRASIL. Ministério do Desenvolvimento Social e Combate à Fome. Secretaria Nacional de Assistência Social. Norma Operacional Básica, NOB/SUAS. Brasília: PNAS, 2004.

BRASIL. Ministério do Desenvolvimento Social. Estratégia Brasil amigo da pessoa idosa. Documento técnico. Brasília: MDS, 2018. 
CDC. Center for Disease Control and Prevention. Covid-19. CDC, 2020.

FARIAS, H. S. D.. O avanço da Covid-19 e o isolamento social como estratégia para redução da vulnerabilidade. Espaço e Economia. Revista Brasileira de Geografia Econômica, v.9, n.17, 2020.

FENZ, K.; KHARAS, H.. Uma perspectiva de mortalidade no COVID-19: tempo, localização e idade. 2020.

GOMES, F. A. R.. Isolamento horizontal versus isolamento vertical no combate à covid-19. Departamento de Economia da FEA-RP, 2020

IBGE. Instituto Brasileiro de Geografia e Estatística. Número de idosos cresce $\mathbf{1 8 \%}$ em $\mathbf{5}$ anos e ultrapassa $\mathbf{3 0}$ milhões. Rio de Janeiro: IBGE, 2017.

MARTINS, S.; RIBEIRO, A. Q.. Das políticas às ações: direitos da pessoa idosa no Brasil. Revista Científica de Direitos Humanos, Brasília, v.1, p.58-81, 2018.
MESA, C. V.; FRANCO, O. H.; GOMES, R. C.; ABEL, T.. COVID19: As prioridades esquecidas da pandemia. Maturitas, 2020.

MONTEMERLI, R.. Os desafios da Itália na emergência do coronavírus. Espaço e Economia, Revista brasileira de Geografia Econômica, v.9, n.17, 2020.

PAULA, C. E. A.; SILVA, A. P.; BITTARR, C. M. L.. Vulnerabilidade legislativa de grupos minoritários. Ciência \& Saúde Coletiva, v.22, n.12, p.3841-3848, 2017. DOI: http://doi.org/10.1590/1413-812320172212.24842017

REIS, A. O.; MARTINS, S.; PINTO, T. R. G. S.. Estratégia Brasil Amigo da Pessoa Idosa em governos locais brasileiros: análise sob a perspectiva dos múltiplos fluxos de Kingdon e do modelo top-down e bottom-up. GIGAPP Estudios Working Papers, v.7, n.162, p.411-428, 2020.

TODD, N.. Ageism: Prejudice against our feared future self. Journal of Social Issues, v.61, p.207-221, 2005. DOI: http://doi.org/10.1111/i.1540-4560.2005.00402.x

A CBPC - Companhia Brasileira de Produção Científica (CNPJ: 11.221.422/0001-03) detém os direitos materiais desta publicação. Os direitos referem-se à publicação do trabalho em qualquer parte do mundo, incluindo os direitos às renovaç̃oses, expansões e disseminações da contribuiç̃o, bem como outros direitos subsidiários. Todos os trabalhos publicados eletronicamente poderão posteriormente ser publicados em coletâneas impressas sob coordenação da Sustenere Publishing, da Companhia Brasileira de Produção Científica e seus parceiros autorizados. Os (as) autores (as) preservam os direitos autorais, mas não têm permissão para a publicação da contribuição em outro meio, impresso ou digital, em português ou em tradução. 